\title{
Representações Sociais dos Alunos da Rede Pública de Ensino do Distrito Federal Sobre a Sociologia no Ensino Médio
}

\author{
Erlando da Silva Rêses ${ }^{1}$
}

\begin{abstract}
Resumo
0 presente artigo ressalta a instabilidade da presença da Sociologia no ensino médio brasileiro e posiciona a situação da disciplina no âmbito do Distrito Federal. Tanto os documentos oficiais quanto os professores da disciplina concordam que ela é um conhecimento dinâmico, flexível e prático, que prepara o educando para o exercício pleno de sua cidadania. Entretanto, é ressaltada a posição do aluno acerca do ensino de Sociologia. Nesse sentido, é apresentado o resultado de uma dissertação de mestrado, que focalizou estudantes do $3^{\circ}$ ano do ensino médio, distribuídos em grupos focais na cidadesatélite de Santa Maria e na Asa Norte de Brasília-DF. A teoria das Representações Sociais serviu como orientação ao desenvolvimento teórico-metodológico, em que Serge Moscovici e Willem Doise foram os principais representantes. Este último autor desenvolveu uma perspectiva societal para o estudo das representações sociais: a existência de um conteúdo comum nas representações sociais das tomadas de posição, a existência de diferenças dentro desse conteúdo comum e a existência de uma ancoragem das diferentes tomadas de posição.

Palavras-chaves: Sociologia da Educação. Ensino de Sociologia. Representações Sociais.
\end{abstract}

\begin{abstract}
The present article emphasizes the instability of the Sociology presence in Brazilian high school and places the situation of the subject in Distrito Federal scope. Both the official documents and the teachers of the subject agree that it is a dynamic knowledge, as well as flexible and practical, that prepares the pupils for the entire exercise of their citizenship. However, the students' opinion about the Sociology teaching is emphasized.

In this sense, it is presented the result of a Master's degree dissertation that focused students of the third year of high school, distributed in focal groups in Santa Maria and

${ }^{1}$ Mestre e doutorando em Sociologia pela Universidade de Brasília. Email: erlandoreses@uol.com.brou erlando@unb.br


Asa Norte, in Brasilia, Distrito Federal. The theory of the social representations served as an orientation to the theoretical and methodological development, in which Serge Moscovici and Willem Doise were the principal representatives. The latter developed a social perspective to the studies of social representations: the existence of a common content in the social representations of the positions, the existence of differences within that common content and the existence of an anchorage of the different positions.

Key words: Sociology of Education. Sociology Teaching. Social Representations.

F alar da Sociologia no Ensino Médio é motivo de orgulho e satisfação. Orgulho por ser parte da rotina de trabalho de professor na Rede Pública de Ensino do Distrito Federal, desde 1998. A satisfação é justificada pela oportunidade de participar da reelaboração do currículo de Sociologia das escolas públicas, em 2001; além de vários outros momentos que envolvem seminários, encontros, fóruns, ciclos, jornadas, debates e discussões sobre o ensino da disciplina tanto no País como no DF.

Uma grande conquista na trajetória dessa disciplina foi a ampliação da sua carga horária no Distrito Federal. A partir de 2000, ela passou a constar nas três séries do ensino médio com carga horária de $2 \mathrm{~h} / \mathrm{a}$ em cada série.

A nova situação da disciplina no ensino médio favoreceu o desenvolvimento da pesquisa sobre as representações sociais dos alunos da rede pública do Distrito Federal. 0 aluno da $3^{a}$ série do ensino médio, que foi o sujeito informante, cursou uma carga horária maior de aulas de Sociologia. Portanto, é possível supor, a partir da análise desenvolvida pelo psicólogo social Serge Moscovici, que a disciplina é um objeto de pesquisa em representações sociais por fazer parte do cotidiano dele. 0 aluno discute, debate e apresenta concepções a respeito dela.

A Teoria das Representações Sociais apresenta dois universos de pensamento. Os universos consensuais, universos de pensamento, nos quais, o indivíduo, com base no senso comum, é livre para manifestar opiniões, propor teorias e respostas para todos os problemas e os universos reificados. Espaços regidos pela lógica científica, onde, o indivíduo tem a participação condicionada pela sua qualificação, isto é, pelo domínio reconhecido de um saber específico (MOSCOVICI, 1981).

Uma das indagações centrais dessa teoriaéjustamente em relação às modificações sofridas pelo conhecimento científico quando ele passa do âmbito dos universos reificados para o âmbito dos universos consensuais. Em outras palavras, quais as transformações que ocorrem com um certo conhecimento sistematizado em função da sua passagem do domínio especializado para o domínio popular? Para Moscovici (1961), seria nesse processo que surgem as representações sociais, verdadeiras teorias do senso comum.

A investigação iniciou-se com uma questão: como a aluno percebe o papel da 
Sociologia em sua formação escolar? Ele constantemente pergunta: para que serve a Sociologia? Esta pergunta não é isenta de sentido. Ela, por exemplo, não consta nos exames vestibulares das faculdades e universidades em Brasiliae, recentemente, passou a constar de forma interdisciplinar do Programa de Avaliação Seriada (PAS) ${ }^{2}$ do Centro de Seleção e Promoção de Eventos (CESPE), da Universidade de Brasília

Em uma incursão no âmbito da pesquisa sobre o ensino da Sociologia o autor não encontrou nenhuma que focalizasse o papel da Sociologia no ensino médio sob a ótica do aluno enaperspectivada Teoriadas Representações Sociais. Muitospesquisadores 3 já realizaram estudos sobre o ensino de Sociologia no nível médio, mas todas pela ótica do professor.

Um momento relevante na história da disciplina no nível médio no Distrito Federal éo debate posto no âmbito dos exames seletivos do Programa de Avaliação Seriada (PAS) e do vestibular da Universidade de Brasília (UnB). No segundo semestre de 2003, por meio de gestões feitas pelo Departamento de Filosofia e por professores de Sociologia das escolas públicas do DF à instância gestora do PAS, ou seja, a Comissão Especial de Acompanhamento do PAS (CESPE/UnB), ${ }^{4}$ foi realizado o evento: "Ciclo de Palestras sobre a Visibilidade da Filosofia e da Sociologia no PAS e no Vestibular da UnB", no período de 29/09 e 1\%/10 ( $1^{\mathrm{a}}$ etapa) e 27 e 29/10/2003 ( $2^{\mathrm{a}}$ etapa).

Apartir desse evento, que contou com a participação do Departamento de Filosofia e Departamento de Sociologia da UnB, de coordenadores pedagógicos das escolas públicas, de professores de Filosofia e Sociologia da rede pública e particular, de integrantes da Secretaria de Educação do DF, a Comissão Especial de Acompanhamento do PAS emitiu documento que criou a Subcomissão Assessora - Filosofia/Sociologia, com o papel de construir objetos de avaliação para o processo seletivo do PAS. ${ }^{5}$ Não se trata de definir mais componentes disciplinares, mas de explicitar e ampliar os vínculos da Filosofia e da Sociologia com as habilidades propostas nos atuais objetos de avaliação das três etapas que compõem o Programa.

\footnotetext{
${ }^{2}$ Este programa configura-se como uma forma de integração entre os sistemas de educação básica e superior, que inclui a seleção dos futuros estudantes universitários de modo gradual e sistemático. No PAS, o acesso aos cursos da UnB não é o produto de um único e episódico exame seletivo, mas a culminância de um processo que se desenvolve ao longo do ensino médio. BRASÍLIA. Universidade de Brasília. Programa de Avaliação Seriada. PAS: Objetos de Avaliação. Apresentação. Disponível em: www.cespe.unb.br/pas . Acesso em: 21 de junho de 2003. Os conhecimentos da Sociologia aparece de forma diluída nos Objetos de Avaliação do referido Programa.

${ }^{3}$ Citamos alguns desses pesquisadores: GIGLIO (1999); MEUCCI (2000) e SANTOS (2002).

${ }^{4}$ Essa Comissão conta com representantes da Universidade de Brasília, da Secretaria de Educação do DF e das escolas particulares do DF.

${ }^{5}$ Essa Subcomissão está atualmente construindo interfaces de conhecimento com as outras áreas que compõem 0 conjunto de componentes curriculares exigido para o exame seletivo do PAS. A idéia é dar maior visibilidade tanto à Sociologia como à Filosofia nesse sistema de ingresso ao ensino superior. A intenção é que passe a vigorar na $1^{a}$ etapa do Subprograma de 2006 do PAS.
} 


\section{A (Des) Institucionalização da Sociologia do Ensino Médio}

A presença da Sociologia no ensino médio sofreu uma descontinuidade ao longo da história da educação no Brasil. Situar esse histórico ajuda a compreender as representações sociais acerca do seu ensino. Costa Pinto, por exemplo, acentuou que a oscilação irregular da Sociologia como disciplina no sistema educacional brasileiro atendeu às inspirações ideológicas do momento histórico. Neste sentido, épossível sustentar que o conceito de cidadania, subjacente ao ensino de Sociologia, só ganha significado em regimes democráticos e tem diferentes reflexos na compreensão do papel da Sociologia (PINTO apud FERNANDES, 1976). 0 figura abaixo revela essa descontinuidade e 0 contexto sócio-político subjacente a cada época. ${ }^{6}$

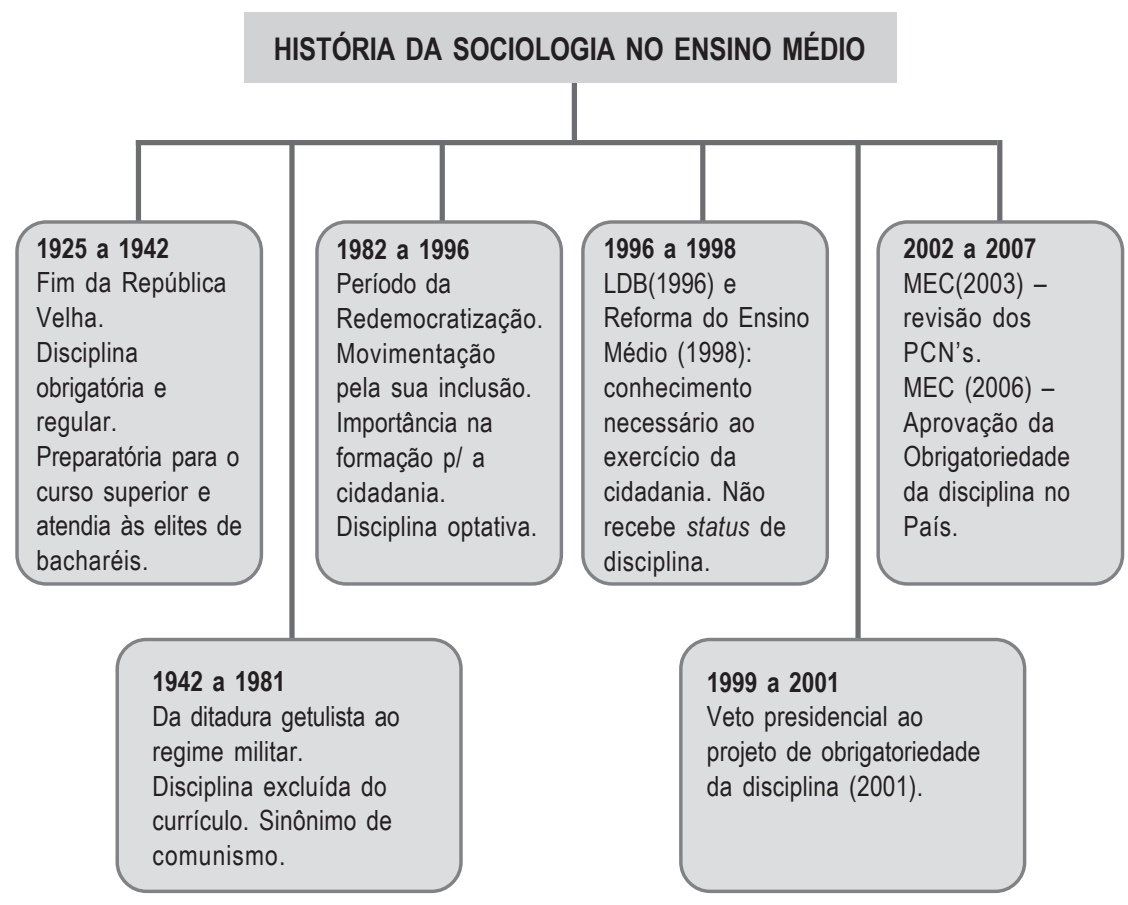

Figura 1 - História da Sociologia no Ensino Médio.

No primeiro período (1925 a 1942) o ensino de Sociologia esteve voltado à inserção social passiva e harmônica do indivíduo na sociedade. Ou visava a sua inserção nos valores normativos da organização social republicana ou ao atendimento dos filhos das elites, objetivando o êxito na progressão dos estudos. Esse modelo foi absorvido pela elite governante como recurso necessário à modernização do País.

${ }^{6}$ Quadro elaborado pelo autor. 
Costa Pinto em sua tese de livre-docência, intitulada "0 Ensino de Sociologia na Escola Secundária Brasileira”, de 1947, chegou a arriscar os motivos das flutuações da Sociologia na escola secundária. Segundo ele, a aversão da legislação vigente ao ensino das ciências sociais é uma das suas características centrais, atestando que "a difusão de noções científicas sobre a organização econômica, social, política e cultural, é menosprezada como objeto de instrução e quase temida como instrumento de educação" (PINTO apud FERNANDES, 1976, p.111).

No regime ditatorial de 1964 acentuou-se o esquecimento da Sociologia no ensino secundário. Ela foi entendida como sinônimo de comunismo e o seu ensino servia de "aliciamento político", portanto, perturbava o regime e a sua presença era um indicador de periculosidade para as elites (PENTEADO, 2002).

A disciplina só foi lembrada novamente na redemocratização do País. Em 1982 é aprovada a lei 7.044, que propõe o fim da obrigatoriedade da profissionalização no $2^{\circ}$ grau porque se percebeu que não estava se efetivando nem a preparação para o mercado de trabalho, nem para a continuidade dos estudos no ensino superior. 0 ensino de Sociologia passa a constar da parte diversificada do currículo, principalmente nos cursos acadêmicos. A tônica da profissionalização começa a ceder terreno para uma concepção de educação mais abrangente, permitindo pensar uma escola de ensino médio voltada para a construção do direito à cidadania, uma das fontes de revitalização da Sociologia (MEKSENAS, 1994). 0 texto da lei 7.044/82, que sugeria que os currículos de ensino deveriam atender conforme necessidade e possibilidade concretas, às peculiaridades locais, aos planos dos estabelecimentos de ensino e às diferenças individuais dos alunos, possibilitaram que a Sociologia ganhasse espaço em alguns Estados brasileiros. Como foram os casos de São Paulo, Rio de Janeiro, Minas Gerais, Pará, Pernambuco, Rio Grande do Sul e Paraná.

No caso do Distrito Federal, ela foi incluída como disciplina do $2^{\circ}$ grau em 1985. A partir de então, passou a integrar como disciplina obrigatória da parte diversificada do curso acadêmico, com carga de duas horas semanais no $3^{\circ}$ ano, e também como disciplina obrigatória da parte profissionalizante do curso normal, com carga de duas horas no $1^{\circ}$ ano.

Na nova LDB (Lei n 9394/96) apareceu um artigo ambíguo sobre o ensino de Sociologia. 0 artigo 36, $\S 1^{\circ}$, inciso III, estabelece o domínio dos conhecimentos de Filosofia e Sociologia como necessário ao exercício da cidadania. Ou seja, elas não estão sendo definidas como disciplinas obrigatórias para o ensino médio. As Diretrizes Curriculares Nacionais para o Ensino Médio (DCNEM), Parecer 15/98 do Conselho Nacional de Educação, que deu base aos Parâmetros Curriculares Nacionais 
(PCNEM) modificou toda estrutura curricular do Ensino Médio. Contudo, a ambigüidade que o texto do artigo 36 da LDB apresenta com relação ao ensino de Sociologia, é mantida ou reforçada pelas DCNEM, ou seja, os estudos de Filosofia e Sociologia estarão presentes na área de Ciências Humanas e suas Tecnologias para atender ao referido artigo da LDB, todavia, sem receber o status de disciplinas (BRASIL, 2000).

Nesse sentido, o deputado Padre Roque (PT/PR) apresentou um projeto com esse objetivo, aprovado pelo Congresso Nacional, e vetado na íntegra pelo então Presidente da República Fernando Henrique Cardoso, sob o argumento de que implicará na constituição de ônus para os Estados e o Distrito Federal por conta da criação de cargos para a contratação de professores e que também não há no País profissional suficientemente formado para atender a demanda.

No governo do presidente Lula a discussão sobre a obrigatoriedade da Sociologia é retomada. Em 2003 o então ministro da educação, Cristóvam Buarque, tem interesse na derrubada do veto de FHC e, ainda neste mesmo ano, começa uma revisão dos Parâmetros Curriculares Nacionais, em que a Sociologia faz parte dos grupos de trabalho em seminários regionais e nacional. 0 grupo de trabalho de Sociologia, coordenado pelos professores, Amaury César de Moraes, Elizabeth Guimarães e Nelson Dacio Tomazi apresentaram as Orientações Curriculares Nacionais para o MEC, agora sob o comando do ministro Fernando Haddad e, em 2006, depois de uma ampla participação da sociedade civil organizada é aprovada a obrigatoriedade de Sociologia e Filosofia no Ensino Médio em todo o território nacional.

\section{Representações Sociais dos Alunos do Distrito Federal Sobre o Ensino de Sociologia}

Participaram da pesquisa 79 sujeitos adolescentes, com idade entre 16 e 20 anos, estudantes da $3^{\text {a }}$ série do ensino médio de escolas públicas do Distrito Federal, dos sexos masculino e feminino. A escolha dessa série aconteceu de forma intencional, uma vez que o aluno já obteve conhecimentos de Sociologia na $1^{a}$ e $2^{a}$ séries, portanto, já acumulou um certo grau de aprendizagem sobre a componente curricular em questão, condição necessário para se constituir como objeto de representação social.

Foram feitas entrevistas coletivas, a partir da formação de 06 grupos focais, três na cidade-satélite de Santa Maria ${ }^{7}$ e três na Asa Norte (Região Administrativa de

7 Surgido no início da década de 90, este assentamento tornou-se rapidamente um aglomerado urbano com contornos definidos de cidade. Sua criação visou atender o programa de assentamento de famílias de baixa renda do DF, em lotes semi-urbanizados. 
Brasília) ${ }^{8}$ com 13 sujeitos em cada grupo. A escolha dos informantes também teve um caráter intencional para que atendesse ao critério da segmentação dos grupos, ou seja, entrevistas com alunos moradores do assentamento de Santa Maria e com alunos moradores da Asa Norte.

0 critério de segmentação por local de moradia foi relevante para a análise das realidades sociais diferenciadas de inserção do aluno e para a percepção do papel da Sociologia nesse contexto. Quais são as representações sociais da Sociologia em sua formação? Haveria pontos em comuns entre os dois grupos? 0 que os diferencia? Tais diferenças estariam assentadas ou ancoradas em quais fatores? Nas necessidades sociais derivadas dos estratos sociais, nas quais, esses grupos estão inseridos? Questões essas que levaram à utilização da proposta de Doise Clémence, e Lorenzi-Cioldi (1992), que buscaram construir o que consideraram uma abordagem societal na investigação das representações sociais.

Essa abordagem de Doise, Clémence e Lorenzi-Cioldi consideraram as representações sociais como princípios organizadores das relações simbólicas entre indivíduos e grupos. Princípios esses que são geradores de tomadas de posição em função de inserções específicas dos indivíduos no conjunto das relações sociais (DOISE apud JODELET, 2001). Esses autores retomam a perspectiva de Moscovici, no que concerne aos processos responsáveis pela formação das representações sociais: a objetivação e a ancoragem. A objetivação concretiza o abstrato, busca dar naturalidade ao objeto por meio da comunicação enquanto a ancoragem incorpora o não familiar dentro de uma categoria mais familiar.

Cada fase ou etapa dessa abordagem tridimensional que estuda as representações sociais corresponde a uma hipótese específica. Aprimeira hipótese seria a de que diferentes membros de uma população estudada partilham certas crenças comuns concernentes a um dado desafio social. Para Doise, Clémence e Lorenzi-Cioldi (1992), as representações têm origem nas relações de comunicação que supõem pontos de referências comuns aos indivíduos e grupos. A segunda hipótese se refere à natureza das diferenças individuais dentro de um campo comum de representações. Nesse segundo nível de análise foi considerada a tomada de posição dos diferentes grupos sociais (alunos de Santa Maria e alunos da Asa Norte) e não a tomada de posição individual. A terceira hipótese se refere à ancoragem das diferentes tomadas de posição no interior de realidades coletivas. Supõese a hierarquia de valores, as percepções construídas pelos indivíduos, as experiências sociais, a relação entre grupos e a situação de classe como moduladores das tomadas de posição (DOISE apud GUIMELLI, 1994). Com essas hipóteses, os autores procuram

\footnotetext{
${ }^{8}$ A Asa Norte é parte da Área Central de Brasília, conhecida como Plano Piloto.
} 
responder a crítica de que a Teoria das Representações Sociais fundamenta-se na suposição da existência de homogeneidade de pensamento em um dado grupo social. Para eles, com essas hipóteses passa-se da idéia de consenso como um acordo entre indivíduos manifestado pela similitude de opiniões, para idéia de que os indivíduos partilhem referências comuns para a tomada de posições.

Para os autores dessa abordagem, Pierre Bourdieu contribuiu para a construção da explicação societal para o fenômeno das representações sociais. Este autor mostra que esta visão de Doise, Clémence e Lorenzi-Cioldi está além de uma oposição entre conflito e consenso, que é muito presente em estudos e pesquisas. Segundo ele, "as tomadas de posição diferentes, mesmo antagônicas, somente se constituem como tais com relação aos objetos de disputa comuns, estes mesmos postos no espaço do jogo dentro do qual eles são jogados, isto é, o espaço das posições sociais." (DOISE, CLÉMENCE E LORENZI-CIOLDI, 1992, p. 7). É a partir desse enfoque de Bourdieu e Doise e colaboradores que serão apresentadas as tomadas de posição dos alunos de Sociologia do ensino público do DF.

1) Sociologia no ensino médio: instrumento de formação para o exercício da cidadania?

As representações sociais dos alunos sobre a Sociologia indicaram a valorização da disciplina, no que tange ao entendimento maior sobre a sociedade moderna, as instituições e os grupos sociais, à construção do senso crítico e à formação da cidadania. Nesses aspectos, a valorização do conhecimento sociológico foi recorrente na "fala debate" nos grupos focais, ou seja, o aluno percebe a aplicabilidade dos conceitos.

A sociedade é importante, por quê? Porque o bomem é um animal racional, que não consegue viver no mundo individualmente, ele convive em sociedade. Muitas vezes, os conceitos que a gente estuda na sala de aula, especificamente na aula de Sociologia, são coisas bem atuais, dentro de nossa realidade. Então, fala tanto de política, tanto de economia, também de relações humanas [...] Então, você tem essa visão, você tem esses conceitos que você precisa aplicá-los no seu dia-a-dia.

Na visão do aluno, os conceitos da Sociologia são aplicáveis ao cotidiano porque eles estão vinculados à atualidade da realidade social e ajudam na compreensão das relações sociaise da sociedade moderna e essa compreensão se vincula à construção do senso crítico.

Eu acho que a Sociologia trabalha muito bem as desigualdades entre as pessoas. A riqueza é mal distribuida entre as classes e entre as raças também. A Sociologia trabalha muito bem isso. Eu acho importante isso, porque ela mostra cada ponto pra gente, sobre as desigualdades sociais que existem na sociedade.

Ele retrata a necessidade da aprendizagem do conteúdo da disciplina, situando-a 184 - MEDIAÇões, LONDRINA, V. 12, N. 1, P. 177-194, JAN/JUn. 2007 
no mesmo patamar de importância que outras disciplinas e ressaltando a sua obrigatoriedade no ensino médio.

Não adianta você estar sendo guiado pelas matérias comuns. Por que a Sociologia ser opcional? Porque a Sociologia é uma matéria de porte como qualquer outra. Eu acho que é fundamental, ela vai dar mais embasamento para a pessoa.

Adisciplina poderia facilmente ter um baixo grau de importância. Primeiramente, por não compor o leque de disciplinas para os exames seletivos para o ingresso no ensino superior e nem em sua forma alternativa, o PAS. Segundo, a existência de uma oscilação entre inclusão ou exclusão da disciplina nos currículos escolares em diferentes fases da história da educação no Brasil provocou uma instabilidade no conhecimento sociológico, não permitindo a sua transmissão intergeracional, diferentemente, de outras disciplinas. Mas, o aluno apresentou essa importância a partir de uma outra ordem, por exemplo, para a conscientização política e social.

Nós fomos adaptados a crescer numa sociedade fechada, criados pela mídia, educados nesse sistema mediocre. Então, eu acho que a Sociologia é de fundamental importância [...]. O que impede a pessoa de se engajar socialmente e ter voz ativa, ocupar uma posição na sociedade? Acontece que ela simplesmente assiste a Rede Globo todo dia e fica feliz com isso. Teve um bimestre que estudamos violência urbana e a gente deu muito enfoque à questão da cidadania, porque tendemos a criar uma postura de acomodação. Ao invés de você buscar soluções concretas, você cria estratégias de defesa, ou seja, ao invés de ir lá e buscar a raiz do problema e combater isso, você fecha a porta da sua casa, põe um cadeado, não anda de tênis chique a noite, não anda sozinha. Então, eu acho que a cidadania consiste em não apenas se defender, mas também atacar.

Esse discurso do aluno está em consonância com o que foi propugnado como formação específica para o campo das Ciências Sociais nos Parâmetros Curriculares Nacionais. Esse documento salienta que os conhecimentos dessas ciências são imprescindíveis para o desenvolvimento pleno do cidadão (BRASIL, 2000). Atribuição esta também pensada pelos professores da rede pública de ensino do Distrito Federal. 0 grupo de professores pesquisado por Santos (2002) concordou que a Sociologia teria o caráter de formação para o exercício da cidadania, seja para a compreensão das relações sociais, seja para a necessidade de sua intervenção na realidade, visando mudanças no âmbito da comunidade, da família, da vida pessoal e do trabalho.

Nessa fase do estudo, ou seja, no campo comum das representações sociais dos 
sujeitos informantes, a pesquisa revelou que Sociologia é um conhecimento dinâmico, prático e aplicável, que contribui na formação do senso crítico, da cidadania e na compreensão da complexidade da vida social e do funcionamento da sociedade moderna. Quais são, então, as diferenças dentro desse campo comum? 0 local de moradia fez alguma diferença no discurso do aluno? Na segunda fase do estudo serão apresentadas as diferenças nas posições dos grupos focais.

2) Papel da sociologia no ensino médio: um conhecimento pragmático para a vida em sociedade

0 grupo de Santa Maria fez a relação da conquista de direitos com a prática da participação popular.

A Sociologia nos ajuda a abrir os olbos, a ir atrás. Participar mais da política do nosso país. Eu acho também, que a gente tinha mais que acordar um pouco, porque isso não é de boje. É desde o tempo dos coronéis, desde quando o Brasil é Brasil. Eu acho que a nossa geração, a geração que vai vir de nós, tem que abrir os olhos pra não deixar isso mais acontecer.

Florestan Fernandes, discutindo as finalidades do ensino de Sociologia, defendeu que este deveria formar pessoas aptas à participação política: "de fato, é de esperar-se que a educação pelas ciências sociais crie personalidades mais aptas à participação das atividadespoliticas, como estas se processam no estado moderno" (FERNANDES, 1976, p. 111).

No entanto, essa percepção dos sujeitos não se reflete em mecanismos de ação efetiva de participação no meio social em que vivem. 0 sujeito utiliza a afirmação: "[...] E a Sociologia nos ajuda a abrir os olbos, a ir atrás", para demonstrar que a disciplina instrumentaliza para o exercício da participação social. Essa informação do aluno coincide com a defesa da finalidade do ensino de Sociologia feita por Florestan Fernandes e, mais recentemente, com o que está disposto no currículo de Sociologia do DF. ${ }^{9} 0$ eixo estruturador da $3^{\text {a }}$ série do ensino médio é: Indivíduo, Estado $e$

participação política e, no conjunto de dez habilidades há duas que se destacam para análise desse enfoque:

a) Aplicar os conhecimentos das Ciências Sociais e suas tecnologias no entendimento de questões pessoais vinculadas à participação em movimentos estudantis, partidos políiticos, associações, movimentos sociais, ONGs, sindicatos,

\footnotetext{
90 currículo de Ciências Sociais do DF abrange três áreas do conhecimento - Antropologia, Sociologia e Ciência Política - sendo que o enfoque para a $1^{a}$ série é antropológico com o eixo estruturador "indivíduo, cultura e constituição das identidades", para a $2^{a}$ série é sociológico com o eixo "indivíduo, estrutura e mudança social" e para a $3^{a}$ série o enfoque é da ciência política com o eixo "indivíduo, Estado e participação política." 
dentre outros.

b) Identificar as diferentes formas de participação política na relação entre 0 indivíduo, o Estado e a sociedade civil organizada (BRASíLIA, 2002).

Um momento crucial no âmbito da intervenção na realidade social se insere no contexto da percepção sobre a cidade, ainda que seja de pessimismo, quanto à possibilidade de mudança social em sua própria localidade,

Só conseguimos mudar alguma coisa, não aqui em Santa Maria, mas em cidades maiores, através de passeatas.

A formação para a cidadania é bastante recorrente nos textos oficiais que determinaram a reforma do ensino médio. A linha de raciocínio apresentada pelos alunos de Santa Maria permite inferir que essa formação estaria assentada numa orientação pragmática e técnica, em que a atuação dos cidadãos por demandas sociais estariam voltadas, principalmente, para o nível local e diretamente associadas a melhoria da qualidade de vida da cidade, do bairro ou até mesmo de uma instituição. Nesse sentido, a Sociologia assume o papel de aplicabilidade na realidade social, de forma intervencionista.

A necessidade de construção do senso crítico pelo ensino da Sociologia já havia sido apresentada em 1949, no Simpósio sobre o Ensino da Sociologia. Nesse evento, Costa Pinto sugere:

De todas, a preocupação comum - e esse é o escopo do ensino da Sociologia na escola secundária - é estabelecer um conjunto de noções básicas e operativas, capazes de dar ao aluno uma visão não estática nem dramática da vida social, mas que lhe ensine técnicas e lhe suscite atitudes mentais capazes de levá-lo a uma posição objetiva diante dos fenômenos sociais, estimulando-lhe o espírito crítico e a vigilância intelectual que são social e psicologicamente úteis, desejáveis e recomendáveis numa era que não é mais de mudança apenas, mas de crise, crise profunda e estrutural (PINTO apud FERNANDES, 1976, p. 108).

A discussão do grupo de alunos da Asa Norte girou em torno do contexto escolar, da dinâmica de funcionamento da escola, da abordagem teórico-metodológica do professor, da comparação entre a escola pública e a escola privada, da crítica à formação do aluno e da preocupação com o ingresso no ensino superior. Esta situação demonstra um outro nível de preocupação com relação ao ensino de Sociologia. Nesse caso, o que prevalece éa posição que esse ensino ocupa no âmbito da escola pública de ensino médio e como ele deve ser tratado no ingresso ao ensino superior. Nesse contexto, duas posições se destacam:

a) Cobrança direta da inclusão da disciplina no sistema de ingresso ao ensino 
superior.

b) Percepção da presença indireta de temas sociológicos na prova de Ciências Sociais (História e Geografia) no PAS (Programa de Avaliação Seriada).

Aqueles que defendem a cobrança direta da inclusão da disciplina no sistema de ingresso a ensino superior acreditam que ela seria mais valorizada e haveria mais seriedade por parte do aluno, e aqueles que defendem que já existem temas sociológicos na prova de Ciências Sociais acreditam que já há disciplinas demais para estudar e que a tendência do exame para o ingresso no ensino superior é cada vez mais interdisciplinar.

É recorrente, na prática pedagógica dos professores do ensino médio, a preocupação com a vinculação do conteúdo de suas componentes curriculares com o conteúdo do PAS, sobretudo na escola particular, ainda que as determinações curriculares nos programas curriculares não orientem nesse sentido. A ausência da Sociologia na maioria das escolas particulares do DF reforça essa situação. Como não éuma componente curricular presente nos exames de avaliação para ingresso ao ensino superior no Distrito Federal, sua presença nos programas curriculares é dispensável.

0 discurso do aluno da Asa Norte se aproxima de um dos postulados dos parâmetros de avaliação do PAS, qual seja: "adotar como eixos estruturadores da avaliação a contextualização e a interdisciplinaridade, com ênfase no desenvolvimento de competências e habilidades" (BRASÍLIA, 2001). Esse programa, seguindo orientações dos Parâmetros Curriculares Nacionais, adota desde 2001 uma estrutura de avaliação que se compõe em blocos: Artes (visuais, cênicas ou música); Língua Estrangeira (inglesa, francesa ou espanhola); Língua Portuguesa e Literaturas de Língua Portuguesa; Ciências Sociais; Ciências da Natureza e Matemática. Essa estrutura objetivou a tendência de se construir objetos de avaliação articulados em uma só prova, sem divisão de rótulos disciplinares. 0 aluno que está inscrito no Programa já é conhecedor desse modelo de avaliação, por isso, expressa com facilidade a forma de funcionamento das provas. Quando ele explicita que os conhecimentos sociológicos estão englobados nas provas de História e Geografia, demonstra apropriação de conceitos sociológicos e consegue enxergar a presença da interdisciplinaridade.

Posição análoga foi manifestada por um documento da Comissão Especial de Acompanhamento do PAS, dirigido aos participantes do "Ciclo de Palestras sobre a Visibilidade da Filosofia e da Sociologia no PAS e no Vestibular da UnB" ${ }^{10}$, em 27 de outubro de 2003, no qual dispõe:

[...] Não se pensa em definição de mais componentes disciplinares no conjunto dos

\footnotetext{
${ }^{10}$ Esse Ciclo foi realizado na UnB nos dias 29/09, 1\%10; 27/10 e 29/10/ 2003, depois de gestões do Departamento de Filosofia ao CESPE, objetivando dar maior visibilidade a disciplina nos exames seletivos do PAS. A Sociologia integrou este Ciclo depois da manifestação por um documento elaborado por professores da rede pública de ensino do DF e encaminhado à Comissão Especial de acompanhamento do PAS.
} 
objetos de avaliação. Mas tão-somente no realçar de competências, em um espírito também explicitado pelos professores de Sociologia, que implica abordar, 'oficialmente, temas sociológicos, antropológicos e políticos' - e filosóficos, acrescentaríamos. A preocupação reflete a tendência em se construírem objetos de avaliação efetivamente articulados em uma só prova, sem divisão de rótulos disciplinares, o que vai, entendemos, a encontro do próprio intento ora coordenado pelo Departamento de Filosofia com a participação ativa do Departamento de Sociologia.

O sujeito que está explicitando uma preocupação com os mecanismos de desenvolvimento do ensino no interior da escola também manifesta preocupação com a preparação para o processo seletivo do PAS (Programa de Avaliação Seriada) e para 0 vestibular, sobretudo, o da Universidade de Brasília. Os sujeitos são alunos da $3^{\text {a }}$ série do ensino médio, portanto, com fortes possibilidades de demonstrar interesse no ingresso ao ensino superior. Brasília apresenta uma elevada oferta no mercado do ensino superior, ${ }^{11}$ que permite realizar diversas escolhas tanto de curso como de Faculdade/Universidade. Obviamente, esta crescente oferta de cursos superiores não reflete, necessariamente, um maior ingresso de alunos egressos das camadas sociais menos privilegiadas.

Portanto, o aluno da Asa Norte também apresentou uma concepção pragmática para a disciplina. Ele a percebe como parte de sua formação escolar, que contribui para a conscientização política e social. No entanto, essa característica estaria mais próxima da formação implementada pela escola pública do que pela escola particular.

A escola pública está mais preocupada com a formação intelectual e a escola particular com o individualismo. Geralmente, as escolas particulares visam o quê?? Indices, números. O professor vai fazer o quê?? Ele vai fazer com que a maioria dos alunos passe no vestibular [...] 0 aluno de escola pública aprende algo que é essencial para ingressar na universidade, que é a autonomia, a busca, entendeu?

Os sujeitos destacam que a escola pública se preocupa com a formação integral do aluno, ao passo que a escola particular com a mecanização da aprendizagem para a aprovação no ensino superior. Como no grupo anterior, eles apresentam uma concepção de cidadania, mas pela ótica da formação do aluno.

0 debate em torno do papel da escola na vida estudantil associa-se à definição da identidade do grupo de pesquisados nessa localidade (região da Asa Norte). Andrade nos apresenta que, na inserção em diferentes grupos sociais, os indivíduos assumem diferentes

\footnotetext{
${ }^{11}$ Brasília conta hoje com cerca de 87 instituições de ensino superior.
} 
identidades coletivas, buscando a identificação com esses grupos e sentimentos de pertencimento, porém tendem a diferenciar-se, tornando-se autônomos e afirmando-se como indivíduos, sujeitos e atores sociais (ANDRADE apud MOREIRA; OLIVEIRA, 1998).

As representações sociais se explicitam nas hierarquias de valores, nas percepções que os indivíduos constroem das relações entre grupos e categorias e nas experiências sociais que eles partilham com o outro, em função de sua pertença e posição (MOLINER, 1996). Refere-se, portanto, à ancoragem das diferentes tomadas de posição no interior de um grupo social ou de uma população.

A formação para o exercício da cidadania como finalidade da educação ou como fundamento do ensino de Sociologia prescinde de definições precisas e garantias de certas condições de operatividade. Por si só, ela não diz nada. É necessário explicitar os fundamentos do conceito de cidadão, os valores que o suportam e as condições objetivas para efetivá-lo. Os textos dos documentos oficiais da reforma do ensino médio não ressaltam nenhuma concepção ou entendimento acerca de cidadania. Mas, cabe lembrar que a reforma do ensino médio no Brasil se insere no projeto neoliberal global, que redefine a educação e a cidadania em termos de mercado, em que 0 agente político se transforma em agente econômico e os cidadãos em consumidores (CANO, 1999). A idéia fundamental é que os serviços de ensino deveriam ser comercializados livremente, com redução de barreiras e melhoria de acesso aos mercados.

A palavra cidadania, muito mais que o seu conceito, faz parte da maioria dos discursos contemporâneos que circulam em torno da questão política, econômica e social. Mas, a sua presença ubíqua não significa clareza. Fala-se em cidadania, muitas vezes, de forma adjetiva, ilustrativa ou, no máximo, prospectiva, como algo a ser alcançado. Mas como acontece com todas as noções amplas demais, a de cidadania acabou servindo para tudo, o que éo mesmo que não ter serventia alguma. Portanto, é algo que muito se fala e pouco se sabe. Contudo, o aluno apresenta a sua noção sobre o termo. Para ele, é fundamental que ela seja exercida, a partir da conscientização política e social e da conquista de direitos.

É possível perceber essa vinculação da cidadania com a cotidianidade no discurso aseguir:

Eu acho que os movimentos são importantes. Mas, antes desses movimentos, a gente tem que pensar dentro da nossa comunidade, cada um fazer a sua parte. Dentro da Sociologia a gente vê isso, cidadania. E o que é cidadania? Temos que ter os nossos direitos, mas também temos que cumprir nossos deveres. Então, a partir do momento que a gente tem isso em mente, buscamos realizar os nossos deveres, que é de ser um bom cidadão. Muita das vezes você em 
pequenos atos acaba ajudando a comunidade como um todo. Então, um exemplo é a gente, pode até ser banal, jogar lixo na rua. Está ligado à cidadania. Se cada um pensar dessa forma (que é uma coisa banal!): todo mundo joga lixo na rua eu vou jogar também. Você vê a cidade poluida... Vê a sujeira...A aparência...E eu estou falando só da aparência. Então, se no nosso dia-a-dia tentarmos consertar isso, para sermos realmente cidadãos, eu acho que mudaria o mundo. Cada um fazendo a sua parte.

Segundo Heller, a cidadania é o cotidiano, pois a vida cotidiana é a vida de todo o homem. Toda a ação do homem está ligada ao cotidiano, mesmo as ações políticas e sociais. Mas também, não há nenhum homem que viva somente a sua cotidianidade, pois todos estão inseridos num contexto global. Portanto, "o indivíduo é sempre ser particular e genérico" (HELLER, 1992, p. 20). 0 espaço doméstico, segundo Santos (1999), éum espaço privilegiado de luta e poder e a sua politização traduz a democratização das relações sociais legitimadas e produzidas a partir de discriminações.

Santos (1999) apresenta a perspectiva de que o indivíduo é também um criador de direitos e não somente um receptor deles, como na visão harmoniosa da cidadania. Portanto, é um indivíduo que desenvolve a cidadania em seu cotidiano de forma ativa. Cidadania ativa é caracterizada por critérios de participação social e política e cidadania inativa é caracterizada pela apatia política e não atuação em canais legais e legítimos de participação. $^{12}$

Conforme foi apresentado, o grupo de Santa Maria faz alusão à necessidade de conquista de direitos sociais. Esse discurso do aluno ancora-se na realidade sócio-econômica apresentada pela região. Utilizando o parâmetro da UNESCO para a identificação do perfil sócio-econômico de uma população, que se baseia no tripé renda, nível de escolaridade e relaçã̃o emprego/desemprego, a situação é a seguinte:

a) A renda mensal da população economicamente ativa da Asa Norte encontra-se num patamar de 40 salários mínimos, enquanto que a de Santa Maria está numa faixa entre 02 e 10 salários mínimos (BRASÍLIA, 1997).

b) Cerca de $83 \%$ da população encontra-se entre 0 analfabetismo e 0 ensino fundamento incompleto, enquanto que na Asa Norte a mesma faixa de escolaridade éde apenas 22\% (BRASÍLIA, 1997).

\footnotetext{
${ }^{12}$ Carvalho (1987) usa as expressões cidadãos ativos e cidadãos inativos para caracterizar comportamentos diferenciados entre os indivíduos nos primeiros anos da República Brasileira. Os inativos se caracterizavam pela apatia política e queriam principalmente que o governo os deixassem em paz e os ativos empreenderam uma das mais espetaculares ações populares da época: a Revolta da Vacina. A revolta foi conseqüência da obrigatoriedade da vacina contra a varíola a todos os cidadãos, considerada um "despotismo sanitário" para manter a "pureza" da República.
} 
c) Enquanto a taxa de desemprego na Asa Norteéde 9\% em Santa Mariaéde 30\% (BRASÍLIA, 2000).

AAsa Norte possui melhores alocações de equipamentos e serviços coletivos, como asfalto, saneamento básico, luz, postos de saúde, centros culturais, etc, do que em Santa Maria, onde estes bens coletivos apresentam-se em condições bem mais precárias .

Esta situação sócio-econômica dicotômica entre a região "central" de Brasília e a Região Administrativa de Santa Maria marca a diferença no discurso do aluno. Conforme assinalado, o pragmatismo existente no discurso do aluno de Santa Maria se ancora nessa realidade social. Baseado nessa situação épossível inferir que em Santa Maria os chamados direitos fundamentais sequer foram garantidos ou conquistados, diferentemente, dos alunos moradores da Asa Norte. Uma das teses marxista revela que sem acesso aos benefícios materiais da economia, é impossível de ser mantida a cidadania em termos políticos (TORRES, 2001).

Na Asa Norte, a preocupação do aluno é de outra ordem. Como foi possível perceber, a todo instante, o discurso dele girou em torno da preocupação com a escola, com os mecanismos de funcionamento dela e com o ingresso no ensino superior. A cidadania, nesse caso, não se apresenta relacionada somente ao perfil sócio-econômico diferenciado, mas também ao pragmatismo imediato de ascensão educacional. Um fator determinante que permite ancorar essa situação encontra-se no capital cultural proveniente dos pais desses alunos. A pesquisa de campo realizada pelo autor revelou que o nível de escolaridade dos pais dos alunos da Asa Norte, que se localizam entre o ensino médio e a pós-graduaçã̃o, apresentou um índice de $70 \%$, enquanto que, nessa faixa de escolaridade, o percentual entre os pais dos alunos de Santa Maria foi de apenas 10\%.

A percepção do aluno do ensino médio da rede pública do Distrito Federal a respeito da Sociologia aproxima-se das orientações e postulados dispostos nos documentos oficiais das mudanças no ensino médio. A característica fundamental para o ensino da Sociologiaé a formação para o exercício da cidadania. Os dois grupos de alunos pesquisados concordaram com essa perspectiva de formação, sob olhares diferentes: um grupo com um olhar na melhoria das condições de vida e outro com um olhar na progressão escolar. Portanto, o aluno valorizou o ensino de Sociologia em sua formação pessoal. 


\section{REFERENCIAS}

ANDRADE, M. A. A. A identidade como representação e a representação da identidade. $I n$ : MOREIRA, A. S. P.; OLIVEIRA, D. C. (Org.). Estudos Interdisciplinares de representação social. Goiânia, AB Editora, 1998.

BRASIL. Congresso Nacional. Lei de Diretrizes e Bases da Educação Nacional - LDB. Lei no 9.394/96. Brasília, 1997.

Parâmetros Curriculares Nacionais para o Ensino Médio - Bases Legais. Brasília: Ministério da Educação, 2000.

BRASÍlIA. Governo do Distrito Federal. CODEPLAN. Pesquisa de Informações SócioEconômicas das Familias do DF- PISEF/DF. Brasília, 1997.

Governo do Distrito Federal. CODEPLAN. Pesquisa de Informações SócioEconômicas das Familias do DF- PISEF/DF. Brasília,2000.

Secretaria de Educação. Departamento de pedagogia. Currículo da Educação Básica das Escolas Públicas do Distrito Federal: ensino médio. Referenciais Curriculares para o Ensino de Sociologia na Rede Pública do Distrito Federal. Brasília, 2002.

CESPE. Programa de Avaliação Seriada. Objetos de Avaliação. Subprograma 2001. Brasília: Universidade de Brasília 2001.

CANO, W. América Latina: do desenvolvimento ao neoliberalismo. In: FIORI, J.L. Estados e moedas no desenvolvimento das nações.Petrópolis: Ed. Vozes, 1999.

CARVALHO, José Murilo de. Os Bestializados: o Rio de Janeiro e a República que não foi. São Paulo: Companhia das Letras, 1987.

FERNANDES, Florestan. A Sociologia no Brasil: contribuição para o estudo de sua formação e desenvolvimento. Petrópolis: Vozes, 1976.

DOISE, Willem. Atitudes e representações sociais. In: JODELET, Denise (Org.). As representações sociais. Rio de Janeiro: EDUERJ, 2001.

DOISE, Willem; CLÉMENCE, Alain; LORENZI-CIOLDI, Fabio. Prises de position et principes organisateurs des représentations sociales. In: GUIMELLI, Christian (org.). Structures et transformations des représentations sociales. Paris, Lausanne, Delachaux et Niestlé, 1994.

DOISE, Willem; CLÉMENCE, Alain.; LORENZI-CIOLDI, Fabio. Représentations Sociales. Grenoble, PUG, 1992.

FERNANDES, Florestan. A Sociologia no Brasil: contribuição para o estudo de sua formação e desenvolvimento. Petrópolis: Vozes, 1976.

GIGLIO, Adriano. A Sociologia na escola secundária: uma questão das Ciências Sociais no Brasil - anos 40 e 50. Rio de Janeiro: Instituto de Pesquisas do Rio de Janeiro, 1999.

HELLER, Agnes. O Cotidiano e a História. 4. ed. Rio de Janeiro: Paz e Terra, 1992. 
JODELET, Denise (Org.). As representações sociais. Rio de Janeiro: EDUERJ, 2001.

MEUCCI, Simoni. A institucionalização da Sociologia no Brasil: os primeiros manuais e cursos. 2000. Dissertação (Mestrado) - UNICAMP, Campinas.

MOLINER, Pascal. Les conditions d'émergence d'une représentation sociale. In:

Images et représentations sociales. Grenoble, PUG, 1996. p. 33-48 . Capítulo traduzido por Ângela Maria de Oliveira Almeida, Adriana Giavoni, Diana Lúcia Moura Pinho e Patrícia Cristiane Gomes da Costa. Instituto de Psicologia da Universidade de Brasília.

MOSCOVICI, Serge. La Psychanalyse, son image et son public: étude sur la représentation sociale de la psychanalyse. Paris, Presses Universitaires de France, 1961.

. On social representations. In: FORGAS, J P. (Ed.). Social cognition: perspective on everyday undertanding. London: Academic Press, 1981.

PENTEADO, Heloísa. Quem tem medo da Sociologia? In: ENDIPE- ENCONTRO NACIONAL DE DIDÁTICA E PRÁTICA DE ENSINO, 11, 2002, Goiânia, 2002. Anais ... Goiânia, 2002.

PINT0, L.A. Costa. Ensino da Sociologia nas Escolas Secundárias. Revista Sociologia, v. 11, n.3, 1949.

SANTOS, Boaventura de Sousa. Pela Mão de Alice: o social e o político na pós-modernidade. 5. ed. São Paulo: Cortez, 1999.

SANTOS, Mário Bispo dos. A Sociologia no Ensino Médio - o que pensam os professores da Rede Pública do Distrito Federal. 2002. Dissertação (Mestrado) - Universidade de Brasília, Brasília.

TORRES, Carlos Alberto. Democracia, educação e multiculturalismo: dilemas da cidadania em um mundo globalizado. Tradução de Carlos Almeida Pereira. Petrópolis, RJ: Vozes, 2001. 